\title{
OTIMIZAÇÃO OPERACIONAL DE UM MOTOR A GÁS NATURAL DE UMA TERMELÉTRICA ATRAVÉS DA INTEGRAÇÃO EM MALHA FECHADA DOS SISTEMAS DE MONITORAMENTO DA PRESSÃO NOS CILINDROS E DE CONTROLE MOTOR
}

\author{
Clayton Barcelos Zabeu ${ }^{1}$, Alexander Penaranda ${ }^{1}$, André Luiz Martelli ${ }^{1}$, Roberto Salvador ${ }^{1,2}$ e \\ Thomas Stefan Guntert ${ }^{3}$. \\ ${ }^{1}$ CAAR Pesquisa e Engenharia Ltda (CAAR), ${ }^{2}$ Linhares Geração SA (LGSA) e ${ }^{3}$ AVL South \\ América (AVLSA)
}

E-mails: mailto: clayton.zabeu@ @aar.com.br, alexander.penaranda@caar.com.br, martelli@caar.com.br, roberto.salvador@lgsa.com.br e thomas.guentert@avl.com

\section{RESUMO}

Devido ao regime inconstante de chuvas no Brasil nos últimos anos, a maior parte das usinas térmicas concebidas para suplementação sazonal da geração vem sendo despachadas quase que continuamente. Sob este novo cenário, Linhares Geração S.A. - que opera uma planta de 204 MW - iniciou em 2014 um programa para melhoria de performance e confiabilidade de suas 24 unidades geradoras baseadas em motores à pistão que utilizam gás natural como combustível. O programa iniciou-se com o monitoramento em tempo real da combustão nos 20 cilindros de uma unidade geradora, com resultados sugerindo que o monitoramento permanente e atuação em malha fechada no balanceamento de potência dos cilindros seriam ferramentas essenciais para otimização da performance do motor. Este projeto compreende o desenvolvimento deste sistema de monitoramento, acoplado a um novo sistema de controle motor totalmente integrados ao sistema de automação da planta. O desenvolvimento se baseou no sistema de monitoramento de motores a pistão AVL EPOSTM, cuja operação independente provou-se de grande utilidade na identificação de falhas no conjunto de força e manutenção preditiva. $\mathrm{O}$ hardware AVL EPOS ${ }^{\mathrm{TM}}$ foi então adaptado para fornecer em tempo real informação sobre a combustão para a nova unidade de controle motor, cujo software incorporou funções de gerenciamento de combustível e avanço baseados nestes dados. Este artigo descreve os principais passos do desenvolvimento e os resultados do novo sistema.

\begin{abstract}
Due to the lack of rain in Brazil during last years, most of stand-by thermal power plants were dispatched almost continuously. The Brazilian power plant operator Linhares Geração S.A., as one of the power plants in the condition mentioned above, started in 2014 a program to increased engine performance and reliability. This would allow an optimized operation with improved economy of the 204 MW plant, which is equipped with 24 medium-speed gas engines. Therefore, a permanent knowledge of the engine conditions and a closed-loop engine control system were examined as the essential tools. This project involved the development of an integrated solution of engine monitoring, coupled to a new engine control system and to the plant automation system. The basis for this approach was a proven expert condition monitoring system AVL EPOS ${ }^{\mathrm{TM}}$ and the engine control system development with closed loop real-time in-cylinder pressure. This paper describes the main project steps and results.
\end{abstract}




\section{INTRODUÇÃO}

A Usina Termelétrica Luiz Oscar Rodrigues de Melo (UTE LORM) operada pela Linhares Geração S.A. (LGSA) foi construída para atender a demanda estipulada no $6^{\circ}$ leilão da Agência Nacional de Energia Elétrica (Aneel), leilão de energia A-3 de setembro de 2008. À época do leilão, o nível médio de despacho da UTE LORM estimado com base no estuda da Empresa de Pesquisa Energética (EPE) era de duas semanas por ano. Estimava-se que o despacho efetivo fosse mais elevado, alcançando uma média de dois meses por ano e, em casos extremos, de quatro meses por ano.

Em seu primeiro ano operacional, a UTE LORM foi despachada por duas semanas mas, desde maio de 2012, o despacho tem sido praticamente contínuo e a perspectiva é que assim se mantenha pelo horizonte atual de previsão. A elevação do patamar de operação da usina é uma consequência de uma série de fatores: redução do preço do gás natural nos Estados Unidos (em decorrência do aumento da produção de gás não convencional), aumento do preço da energia no Brasil (devido à mudança de metodologia de cálculo do custo de operação do sistema) e a redução do volume de água nos reservatórios das hidrelétricas, que faz com que as termelétricas flexíveis sejam despachadas com maior frequência a fim de suprir déficits de energia nos períodos de pouca chuva ou causados pela variação sazonal do consumo. Dessa forma, o aumento do nível de despacho é estrutural, significando que o modelo operacional da UTE LORM não é mais uma usina 100\% flexível complementar à geração hidráulica, mas sim uma termelétrica que opera na base (base load).

Pelo fato de a UTE LORM, como muitas outras UTEs, não ter sido projetada para operar na base, seu custo operacional se tornou um fator crítico para a sua saúde financeira. A UTE LORM não dispunha de sistemas que objetivassem maiores eficiências no uso de combustível por questões de custo de capital e, caso algum de seus moto-geradores apresentasse interrupções na geração, havia uma penalidade econômica contratual pela inadimplência daquela parcela de energia que deixava de ser fornecida. Esses dois fatores acabaram por conduzir a uma situação na qual a interrupção de operação em qualquer moto-gerador acarretava penalização considerável e, quando gerando, não são observadas condições de máxima eficiência na conversão energética.

Esse cenário então levou à concepção de um projeto de pesquisa de um sistema integrado de monitoramento e diagnóstico - que permitisse a antecipação de falhas que impactassem em paradas não programadas das unidades geradoras - a um sistema de controle-motor - que permitisse a operação em regime ótimo, considerando-se variações na qualidade do combustível, condições ambientais e de deterioração de equipamentos e subsistemas dos motogeradores. Tal sistema integrado, baseado na medição contínua dos valores de pressão no interior de todos os cilindros de um moto-gerador, na avaliação da qualidade do combustível e nas condições atmosféricas operacionais específicas poderá, a princípio, ser aplicada a motogeradores que empreguem motores de ignição por centelha e utilizem gás natural como combustível, e está sendo aplicado em um dos motores da Linhares Geração S.A. (LGSA) como estudo de caso.

O objetivo principal do trabalho corrente é desenvolver um sistema integrado que permita obter uma melhoria da eficiência energética e/ou aumento da capacidade de geração dos motogeradores, por meio da utilização de parâmetros indicados dos motores como variáveis de realimentação do sistema de controle do motor, sempre tendo um sistema de monitoramento 
indicando os limites operacionais e possibilitando aos operadores anteverem potenciais problemas na condução dos moto-geradores. A metodologia utilizada se baseia no acoplamento de um sistema de monitoramento e diagnóstico a partir das curvas de pressão no cilindro com um sistema de controle-motor para aumento da eficiência da combustão individual de cilindros e balanceamento da potência do conjunto de cilindros.

Dados de pressão no cilindro há muito vem sendo usados em pesquisa aplicada a motores de combustão interna, uma vez que a pressão relaciona diretamente a energia química liberada pela combustão ao trabalho disponível no eixo do motor. A ideia de se utilizar a realimentação (feedback) de pressão no cilindro não é nova, trabalhos como [1] e [2] já elucidavam as potenciais aplicações destes dados provenientes da câmara de combustão no controle do tempo de ignição, injeção de combustível e recirculação de gases do escapamento, com efeitos benéficos sobre a performance e eficiência do motor, ao permitir a possibilidade da correção dos parâmetros de operação para compensação de efeitos como variação da composição do combustível, tolerâncias de fabricação e desgaste do motor. A referência [3] aponta o custo dos sensores como proibitivos para aplicações em produção em massa, mas àquela época já havia sido introduzida a técnica para controle do tempo de ignição em aplicações no mercado doméstico do Japão. A referência [4] propõe, em 2000, um conceito alternativo de sensor de baixo custo e exploraram ainda diferentes metodologias para o tratamento dos dados de pressão e atuação em malha fechada considerando diversas funções objetivo, com resultados promissores.

Apesar de diversas tentativas, a aplicabilidade em larga escala desta metodologia esbarra no custo dos sensores, sua confiabilidade e durabilidade [5]. Porém, em meados da década de 2010, o advento de sensores duráveis - ainda que caros - encontrou nos motores industriais um nicho de mercado, onde os benefícios propiciados pela tecnologia podem cobrir os custos de implantação. As referências [7] - [9] empregam metodologia similar à ser empregada na UTE LORM, com resultados indicando potencial margem para aumento da potência disponível e eficiência, bem como redução dos níveis de emissões de óxidos de nitrogênio (NOx), monóxido de carbono (CO) e hidrocarbonetos não queimados (HC). Especificamente no trabalho de Portin e Hellén [8], o motor utilizado é bastante similar ao da UTE LORM, porém os resultados divulgados estão em sua maioria no formato de tendência e em unidades às vezes não definidas, relativizando a quantificação. As aplicações comerciais em motores Wärtsilä SG34 e SG50, Kawasaki da família Green Gas Engine KG e motores GE Jenbacher J920 FleXtra [10] mencionam a quantificação da detonação e pressão máxima no cilindro em seus algoritmos, porém não é claro que tipo de estratégia de controle é efetivamente empregada. Presume-se que estejam limitadas a pressão de pico e detecção de detonação e nestas baseiam-se as estratégias de balanceamento de carga entre os cilindros, tal como exemplificado em [8].

\section{MATERIAIS E MÉTODOS}

A seguir são apresentadas as características do sistema atual, do sistema proposto, passos da implementação e detalhes acerca dos sistemas de medição.

\subsection{CARACTERISTICAS DO SISTEMA ATUAL}

A UTE LORM consome gás natural fornecido pela BR Distribuidora/Petrobras a partir do gasoduto Cacimbas-Vitória e possui uma potência instalada de 204 MW. Cada grupo gerador é acionado por um motor alternativo de combustão interna de quatro tempos, turbo- 
comprimido, modelo Wärtsilä 20V34SG de ignição por centelha (ciclo Otto) com mistura pobre e é alimentado exclusivamente a gás natural com injeção individual por cilindro [11]. A Tabela I mostra suas principais características.

Tabela I. Principais características do motor utilizado.

\begin{tabular}{|c|c|}
\hline Modelo & Wärtsilä 20V34SG \\
\hline Tipo & Estacionário, ignição por centelha, 4 tempos (ciclo Miller) \\
\hline Operação & Regime permanente em carga nominal e rotação constante \\
\hline Potência de eixo & $8.700 \mathrm{~kW}(435 \mathrm{~kW} /$ cilindro $)$ \\
\hline Configuração dos cilindros & $20 \mathrm{em} \mathrm{V} @ 55^{\circ}$ entre bancos de cilindros \\
\hline Diâmetro / Curso do cilindro & $340,0 / 400,0 \mathrm{~mm}$ \\
\hline Volume & 36,32 litros/cilindro \\
\hline Número de válvulas por cilindro & 2 válvulas de admissão e 2 válvulas de exaustão \\
\hline Velocidade nominal & $720 \mathrm{rpm}$ \\
\hline Velocidade média do pistão & $9,6 \mathrm{~m} / \mathrm{s}$ \\
\hline Eficiência mecânica & $90 \%$ \\
\hline Razão volumétrica de compressão & $12: 1$ \\
\hline Turbocompressores & $2 \times$ Napier NA307 Frame EK \\
\hline $\begin{array}{l}\text { Trocadores de calor do sistema de ar } \\
\text { de admissão }\end{array}$ & Vestas Aircoil \\
\hline Ordem de ignição & $\begin{array}{l}\text { A01-B01-A04-B04-A03-B03-A02-B02-A06-B06- } \\
\text { A10-B10-A07-B07-A08-B08-A09-B09-A05-B05 }\end{array}$ \\
\hline
\end{tabular}

Em motores ciclo Otto com cilindros de grande diâmetro, como o empregado pela LGSA, existe uma faixa estreita de operação: para baixas razões de diluição por ar $(\lambda<1,90$ em carga plena a pressão média efetiva de eixo (PME) é limitada pela ocorrência de combustão anormal ("detonação", batida-de-pino ou knock). Para altas razões de diluição por ar ( $\lambda>2,00$ em carga plena), a ocorrência de knock é reduzida sensivelmente, porém a propagação da frente de chama fica muito degradada e ocorrem as falhas de ignição ou combustão parcial (misfire / partial burn). A Figura 1 mostra esquematicamente as regiões de operação normal em cor ciano e em vermelho as condições anormais de operação, nestas condições, as eficiências de conversão são da ordem de $47 \%$ - como indicado pela janela de operação.

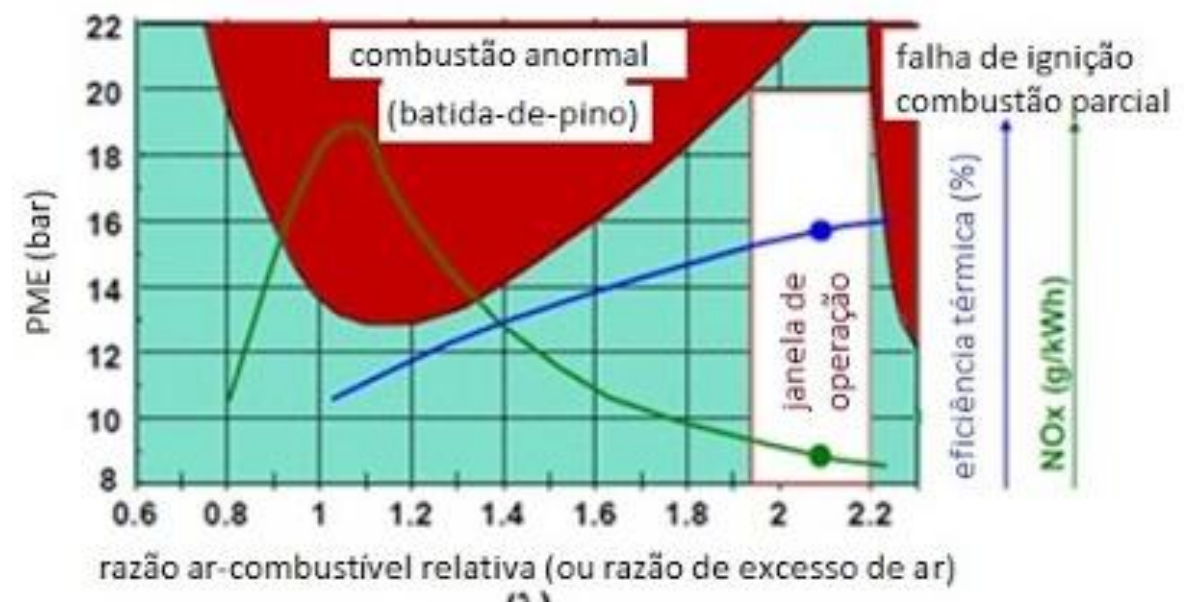

( $\lambda$ )

Figura 1 - Regiões de operação normal e de combustão anormal, adaptado de [11] 
Tal nível de diluição $(\lambda \sim 2,00)$ só é alcançada pelo emprego de pré-câmaras, na qual gás suplementar é fornecido por meio de uma válvula mecânica (Figura 2). A condição de mistura na pré-câmara é levemente rica, sendo facilmente ignitável. Jatos dos produtos da combustão da pré-câmaras são lançados na câmara principal por meio de 6 orifícios criando várias frentes de chama e acelerando a combustão e reduzindo a variabilidade cíclica. Em condições normais, o coeficiente de variação da pressão média indicada nos cilindros não ultrapassa $1 \%$.

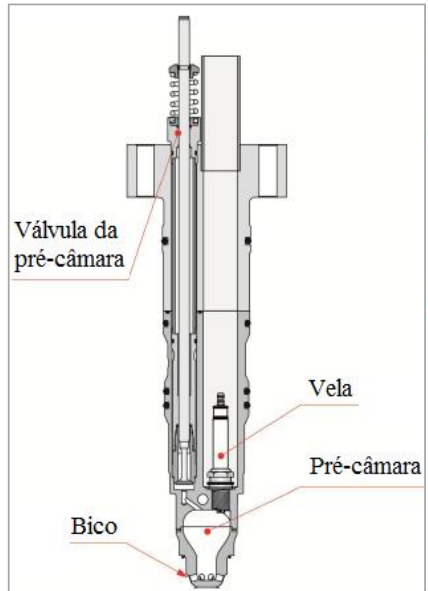

(a)

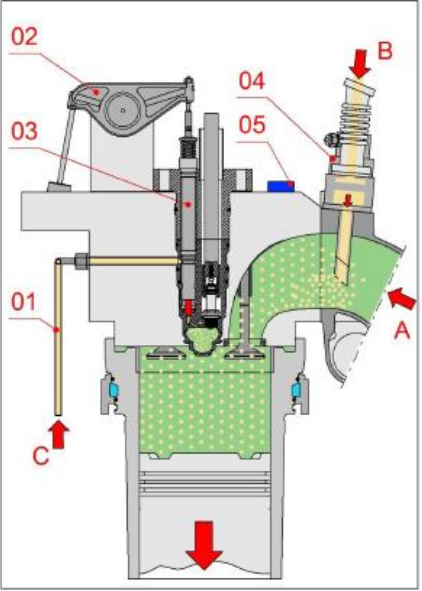

(b)

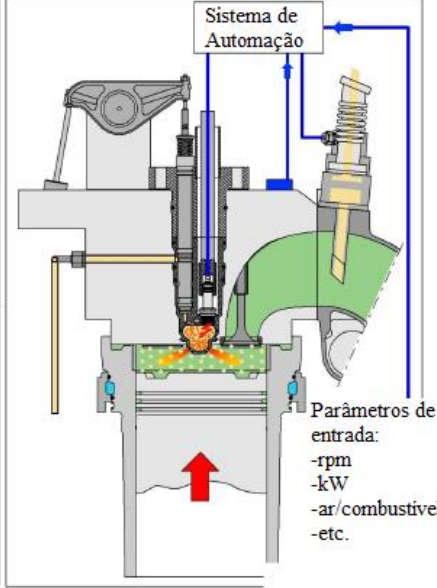

(c)

Figura 2 - Sistema de combustão com pré-câmara: (a) Pré-câmara. (b) A- admissão de ar; B- injeção de gás para câmara principal; C- injeção de gás na pré-câmara; 1 - duto de gás da pré-câmara; 2atuador mecânico; 3- válvula da pré-câmara; 4-válvula principal de injeção de gás; 5- sensor piezoelétrico; (c) instante da ignição, adaptado de [11].

Variáveis como as propriedades do gás natural, condições climáticas, condições de operação e manutenção do motor e suas partes influenciam na potência final disponível do motor e emissões gasosas. Fenômenos de detonação e falha de combustão (knock e misfire) são também críticos para a operação destes motores, requerendo monitoramento e ajustes constantes nas condições de operação $[11,12]$. Apesar das melhorias contínuas desenvolvidas nesse produto, à época da implantação da UTE LORM estes motores não incorporavam conceito de controle da combustão retroalimentada pela pressão nos cilindros, sendo que as limitações do sistema de controle original do motor acabam por restringir a máxima potência desenvolvida por cada cilindro devido à incerteza associada ao método de quantificação do nível de detonação (sensor de vibração do bloco/acelerômetro), reduzindo indiretamente assim a potência disponível do motor para preservar-se a segurança da operação.

A seguir é apresentada brevemente a estrutura atual do controle dos motores W20V34SG (Figura 3), substituída pelo novo sistema integrado ao monitoramento da pressão de combustão:

O módulo de controle principal (MCM - Main Control Module) faz a leitura de informações enviadas pelos demais módulos e realiza o ajuste de velocidade e carga determinando os valores de referência para admissão principal de gás, controle de mistura ar-combustível e tempo de ignição. Este módulo gerencia automaticamente o início e parada de operação e se comunica com o sistema de controle da planta. 
O módulo de controle do cilindro (CCM - Cylinder Control Module) gerencia a mistura arcombustível de até 3 cilindros, ajustando a admissão individual de gás. É também responsável pela medição de temperatura dos gases de exaustão, temperatura da camisa e rolamentos principais e intensidade de detonação, cuja informação é utilizada para ajustar o tempo de ignição e admissão de gás de cada cilindro.

Os IOMs (Input Output Module) são utilizados para conexão de sensores de temperatura e pressão diversos (óleo, água, mancais) e saídas para atuadores auxiliares.

O módulo de segurança (ESM - Engine Safety Module) atua de maneira independente ao módulo de controle principal e é responsável pela proteção redundante do motor. Atua em casos extremos de sobre-velocidade, alta temperatura do motor e baixa pressão de óleo.

No painel de controle local (LCP - Local Control Panel), instalado ao lado do motor, são posicionados o módulo de controle principal (MCM), módulo de segurança (ESM) e o módulo de alimentação (PDM - Power Distribution Module), o qual fornece alimentação 24V de corrente contínua para o sistema de controle. Neste gabinete está instalada também uma unidade de controle local (LDU - Local Display Unit), que permite visualizar graficamente parâmetros, eventos e diagnósticos do motor.

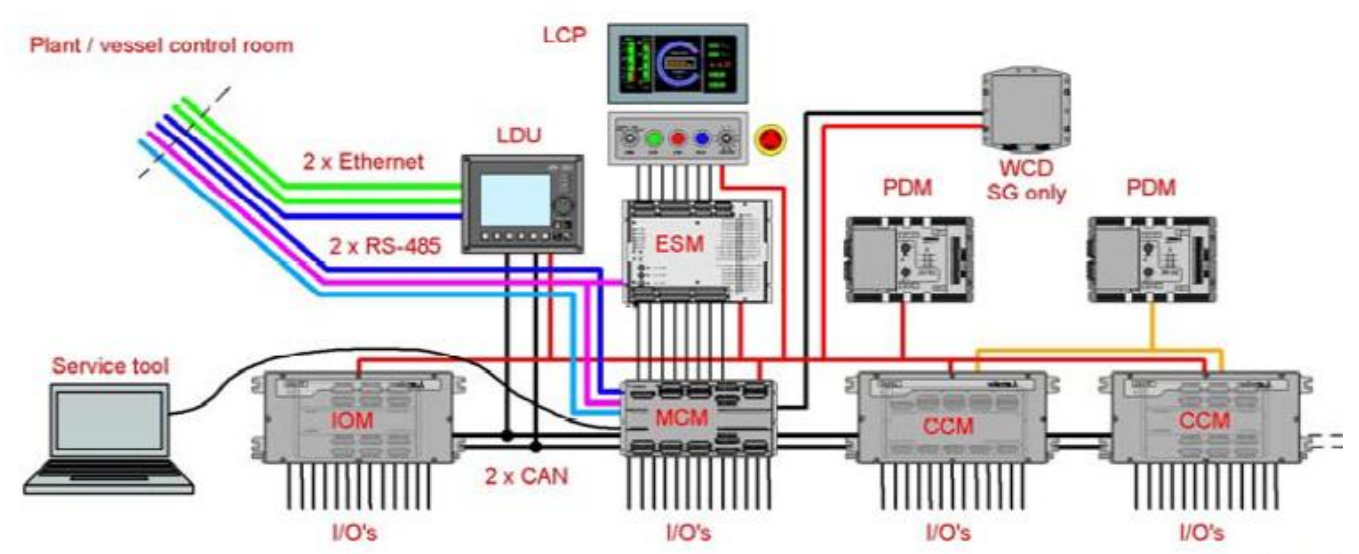

Figura 3 - Módulos do sistema de controle do motor W20V34SG [11].

Com o motor em operação, falhas como detonação elevada, desvio na medição da pressão de gás e temperatura elevada dos gases de exaustão conduzem automaticamente a uma redução de carga por medida de segurança. Eventos de maior risco para o motor, como por exemplo, falha de comunicação da rede CAN, elevada pressão no bloco do motor, temperatura dos gases de exaustão acima de um limite pré-definido, elevada temperatura da camisa do motor ou dos rolamentos, conduzem a um desligamento automático do motor (ou Shutdown). Neste caso, as válvulas solenoides de admissão de gás são desligadas e a linha de gás é ventilada, porém as velas continuam o centelhamento para evitar que gases não queimados alcancem o duto de exaustão. Caso a falha seja ainda mais severa, como por exemplo, velocidade excessiva, sobrecarga ou falha dos sensores de velocidade, o motor sofre uma parada emergencial imediata (Emergency Stop). Além do procedimento de parada supracitado no modo Shutdown, a alimentação das bobinas de ignição é desligada e o motor é imediatamente parado. 
A distribuição relativa da quantidade de combustível entre os cilindros - ou balanceamento da potência - baseia-se em duas estratégias: equalização da temperatura de escapamento (carga < $75 \%$ ) ou da intensidade de detonação (carga $\geq 75 \%$ ). A primeira se baseia em um controlador do tipo PI (proporcional - integral) atuando sobre a quantidade de combustível individual por cilindro, minimizando a diferença entre sua respectiva temperatura de exaustão em relação à média dos 20 cilindros. A segunda atua de forma adaptativa: se um cilindro é identificado como em detonação leve dentro de uma janela estatística, sua quantidade de combustível é reduzida em $1 \%$. Se, no entanto, o nível de detonação é mais elevado, está correção poderá ser de $2 \%$ aplicada em um único passo. O módulo de controle grava em sua memória não volátil os valores relativos de distribuição de combustível para acelerar a convergência do método após paradas, contudo o sistema depende da ocorrência de detonação em dois níveis discretos (leve e alta) para aplicar novas correções. Limitação esta intrínseca a menor precisão propiciada pelos sensores de detonação do tipo piezoelétrico.

Os sistemas de controle hoje oferecidos por vários fabricantes de motores a gás incorporam a quantificação da detonação e pressão máxima no cilindro em seus algoritmos, objetivando operação no limiar entre as regiões de combustão normal e anormal. Em todos, os avanços tecnológicos são protegidos como propriedade intelectual e ainda que comercialmente disponíveis para aplicação em retrofit aos motores existentes, esbarra-se nas questões de custo e na manutenção do paradigma da dependência tecnológica. Este cenário foi também motivador para que o novo sistema de controle fosse desenvolvido.

\subsection{SISTEMA DE MONITORAMENTO}

Como mencionado em parágrafos anteriores, a demanda contínua e não antecipada de operação para usinas que não tenham sido projetadas para essa condição - como a da UTE LORM impacta diretamente na durabilidade de componentes de suas unidades geradoras, exigindo rigoroso controle de manutenção e monitoramento para assegurar a disponibilidade de seus equipamentos. Porém, ainda que seguindo as melhores práticas de gestão em operação e manutenção, as ferramentas de monitoramento fornecidas pelos fabricantes das unidades geradoras são deficientes para uma termelétrica que opera na base e são passíveis de melhoria, dada as condições extremas a que os equipamentos são submetidos.

Ao investigar oportunidades de melhorias e com base em pesquisas do estado da arte na área, verificou-se que os diagnósticos baseados em pressão de cilindro são os mais promissores. Verificou-se ainda que os motores da UTE LORM possuem em seus cabeçotes orifícios que permitem a instalação de sensores para medição de pressão na câmara de combustão, similar aos motores mais modernos que já contam com esta tecnologia.

Após busca de transdutores disponíveis no mercado para esse tipo de aplicação, foi escolhido o transdutor tipo piezoeléctrico da marca AVL, modelo GO41DA-C. A Tabela II traz as principais características desse sensor, confeccionado com cristal de ortofosfato de gálio $\left(\mathrm{GaPO}_{4}\right)$, com amplificador de carga integrado e com saída de 4-20mA. A Figura 4 mostra o sensor e seu o local de instalação nos cabeçotes do motor Wärtsilä 20V34SG. 
Tabela II. Principais características do transdutor de pressão no cilindro.

\begin{tabular}{|l|l|}
\hline \multicolumn{2}{|c|}{ Especificação do sensor de pressão GO41DA } \\
\hline Faixa de medição & 0 a 250 bar \\
\hline Sobre pressão & $300 \mathrm{bar}$ \\
\hline Vida útil & $\geq 10^{9}$ ciclos de carga \\
\hline Linearidade & $\leq \pm 0,5 \%$ \\
\hline Frequência natural & $90 \mathrm{kHz}$ \\
\hline Sensibilidade de aceleração & $\leq 0,002 \mathrm{bar} / \mathrm{g}$ axial \\
\hline Resistência ao choque & $\geq 2000 \mathrm{~g}$ \\
\hline Resistência de isolação & $\geq 10^{13} \Omega$ em $20^{\circ} \mathrm{C}$ \\
\hline Capacitância & $7 \mathrm{pF}$ \\
\hline Temperatura operacional & -40 a $350^{\circ} \mathrm{C}$ \\
\hline Mudança de sensibilidade térmica & $\leq 0,5 \%$ em 20 a $350^{\circ} \mathrm{C}$ \\
$\leq \pm 0,2 \%$ em $250 \pm 100^{\circ} \mathrm{C}$ \\
\hline Alteração de drift de carga & $1,5 \mathrm{mbar} / \mathrm{ms}$ \\
\hline & $\Delta \mathrm{p} \leq \pm 0,4 \mathrm{bar}$ \\
$\Delta \mathrm{pmi} \leq \pm \pm 1,5 \%$ \\
Erro de choque térmico & $\Delta \mathrm{pmax} \leq \pm 0,5 \%$ \\
\hline Diâmetro da rosca de conexão & $\mathrm{M} 14 \times 1,25$ \\
\hline Peso & $34 \mathrm{~g}$ sem cabo \\
\hline Torque de montagem & 20 a $25 \mathrm{~N} . \mathrm{m}$ \\
\hline
\end{tabular}

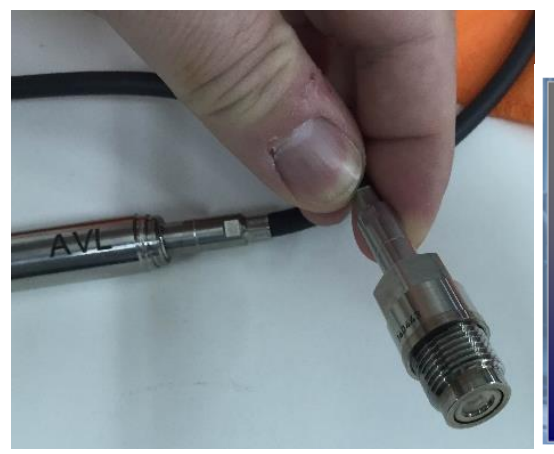

(a)

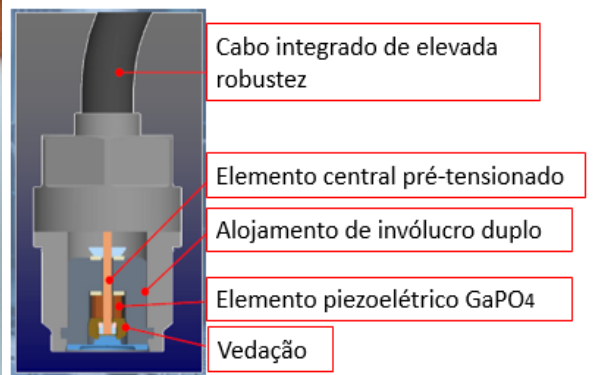

)

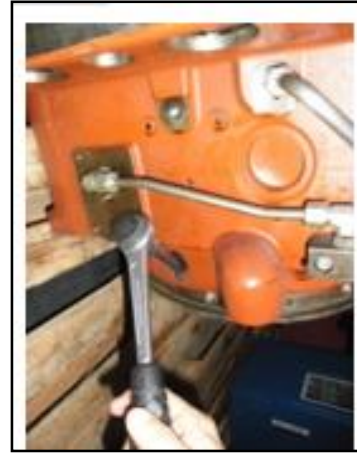

(b)

Figura 4. Detalhes do transdutor de pressão AVL GO41DA-C (a) e local de instalação do transdutor no cabeçote (b).

Para o monitoramento e diagnóstico das condições dos cilindros, um sistema computacional baseado em modelos de fenômenos físicos que ocorrem durante a admissão, a compressão, a ignição, expansão e escapamento, associado à lógica fuzzy, foi customizado para as condições do motor Wärtsilä 20V34SG. Esse sistema é denominado EPOS ${ }^{\mathrm{TM}}$ - Engine Performance and Optimization System [14, 15] e está sendo desenvolvido pela empresa AVL inicialmente com foco em motores pesados marítimos. Tal sistema compreende, além dos transdutores de pressão, módulos de alta taxa de aquisição de dados (denominados SIU - Smart Indicating Units), comunicação via ethernet e um computador que gerencia as aquisições e efetua os diagnósticos. Cada módulo possui 8 canais que gravam os sinais de pressão a uma taxa de até 50k amostras/s e 16 bits de resolução. A Figura 5 mostra um módulo SIU e o conjunto dos 3 módulos instalados no painel elétrico situado ao lado do motor de ensaio. 

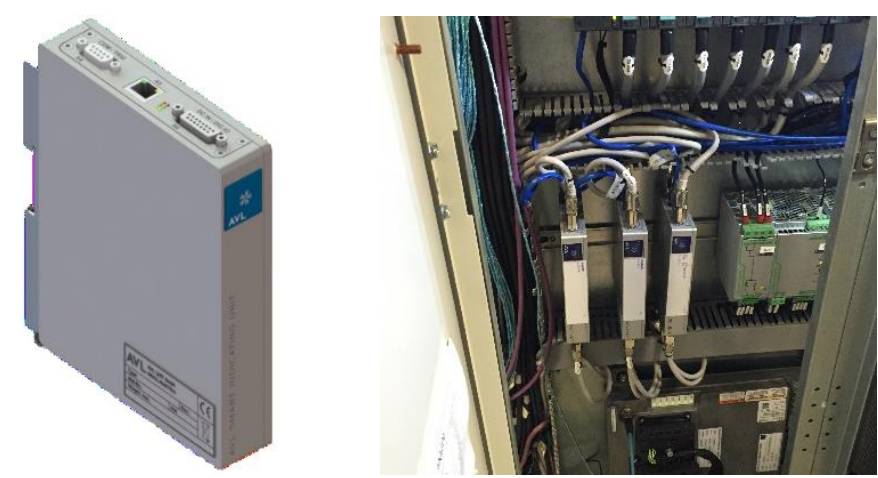

Figura 5. Módulo de aquisição rápida de sinais de pressão (SIU - Smart Indicating Unit) e instalação em painel elétrico

Os algoritmos contidos no EPOS ${ }^{\mathrm{TM}}$ consideram que cada tipo de sintoma pode estar associado a um ou mais tipos de falhas. Atribuindo-se pesos ao impacto de cada tipo de falha a um sintoma, é possível criar uma "nota" para cada tipo de falha, possibilitando assim a indicação automática pelo sistema da condição do motor para cada tipo de falha característica. A Tabela III mostra, como exemplo, uma tabela de relação entre tipos de sintomas detectáveis pelas curvas de pressão no cilindro e as respectivas possíveis falhas. A Figura 6 traz esquematicamente o procedimento de avaliação da probabilidade de tipo de falha está associada a um ou mais sintomas.

Tabela III - Tabela de inter-relacionamento entre sintomas e possíveis falhas associadas

\begin{tabular}{|c|c|c|c|c|c|}
\cline { 2 - 6 } \multicolumn{1}{c|}{} & Falha 1 & Falha 2 & Falha 3 & $\ldots$ & Falha n \\
\hline Sintoma 1 & + & + & - & $\cdots$ & 0 \\
\hline Sintoma 2 & 0 & - & 0 & & 0 \\
\hline Sintoma 3 & - & + & 0 & & 0 \\
\hline$\ldots$ & & & & & \\
\hline Sintoma m & - & + & 0 & & + \\
\hline
\end{tabular}
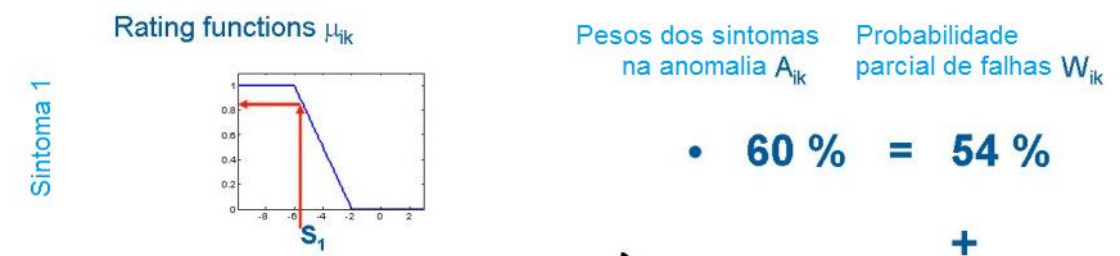

- $60 \%=54 \%$

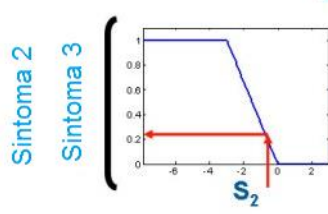

AND (MIN)

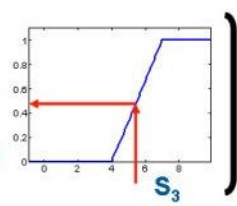

- $25 \%=5 \%$

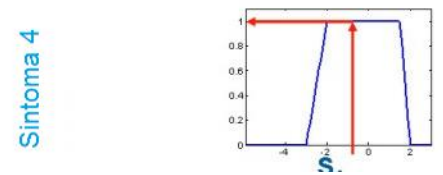

- $15 \%=15 \%$

Figura 6. Exemplo de tabela de sintomas, pesos e resultado da ponderação de um tipo de falha.

Para que o sistema de aquisição de dados baseado nas SIUs tivesse a capacidade de processamento em tempo real das curvas de pressão para geração de parâmetros que indicam a ocorrência e intensidade dos fenômenos de knock e subsequente envio dos mesmos para um sistema de controle, foi necessário modificar tanto hardware como firmware das SIUs. Foi adicionada uma porta de comunicação rápida via rede de controle local (controller area network 
- CAN) que permitiu que os seguintes parâmetros processados pelas SIUs fossem enviados a central de controle do motor:

- pressão máxima de ciclo (peak pressure);

- localização da pressão máxima de ciclo (peak pressure location);

- pico de pressão de knock após filtragem (knock peak)

Para uma apropriada identificação dos fenômenos de knock, foram realizadas medições no motor em dois cilindros, com uma resolução de $0,1^{\circ}$ de ângulo de virabrequim na região de $0^{\circ}$ até $70^{\circ}$ após do ponto morto superior. Pela indução de detonação através do aumento da quantidade de combustível em um dos cilindros foi definida experimentalmente que frequências na faixa de 1 até $1,5 \mathrm{kHz}$ possuem as maiores amplitudes de pressão quando da incidência de knock. Assim, para quantificar apropriadamente estes fenômenos, o circuito de entrada e filtros de frequência das SIUs foram configurados de forma a não atenuar esta faixa de interesse.

\subsection{NOVO SISTEMA DE CONTROLE}

Considerando que o sistema de controle atual da Wärtsilä foi desenvolvido em base a uma topologia modular (Figura 3), onde diferentes tipos de motores e condições operacionais são atendidos, foi definida uma nova topologia que simplificasse o número de componentes e permitisse a integração dos sistemas supervisório da usina e de diagnóstico da pressão do cilindro. Esta topologia tem como base uma unidade de controle-motor que melhor se enquadrou às necessidades do projeto e que permite o desenvolvimento de estratégias de controle em base ao software Matlab/Simulink. A escolha recaiu sobre o LECM (Large Engine Control Module) fornecida pela Woodward, fabricante tradicional no ramo de sistemas de controle e atuadores para motores industriais.

O LECM foi desenvolvido sobre uma plataforma modular, concebida para atender a maioria das tendências observadas no desenvolvimento recente de motores industriais, desde o ponto de vista de atuadores (válvulas de injeção individuais por cilindro) ao aumento da complexidade dos sistemas de diagnóstico e estratégias de controle. A Figura 7 mostra uma imagem de um módulo LECM e sua montagem no painel elétrico ao lado do moto-gerador de ensaio.

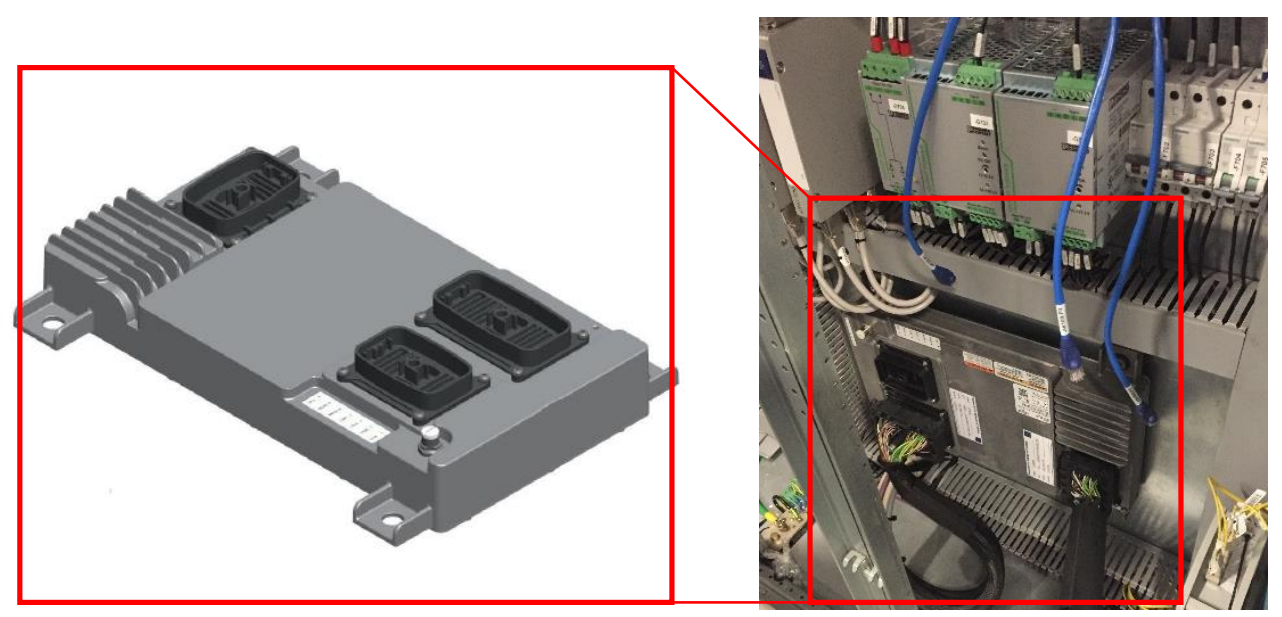

Figura 7. Imagem de uma LECM e sua montagem no painel elétrico.

Como principais atributos do LECM, destacam-se: 
- Alta capacidade de processamento com dois microprocessadores:

- Freescale MPC5566, $126 \mathrm{MHz}$ que processa software da aplicação

- Freescale MPC5644, $147 \mathrm{MHz}$ dedicado ao gerenciamento dos atuadores

- Diversas linhas de comunicação para integração com a usina:

- CAN, RS-485, RS-232 e 10/100 Ethernet

- Diversas entradas/saídas digitais e analógicas

- capacidade de para incorporação de novos sensores e funções.

- Acionamento das 20 válvulas de gás a partir do mesmo hardware.

A cargo do LECM ficam todas as funções críticas envolvendo o controle da combustão e reação de falhas de seus atuadores diretos (ignição e injeção), tarefas estas que requerem determinismo no processamento. De forma resumida, a LECM recebe via interface com o controlador lógico programável (CLP) da planta variáveis de processos e comandos de partida, parada e potência requerida ajustada no sistema supervisório da usina, atuando sobre o momento da ignição e a quantidade de combustível a ser suprida a cada cilindro considerando limitações físicas ajustadas (máximo tempo de injeção e mínima razão de diluição) e de segurança (intensidade de detonação, máxima pressão no cilindro) avaliadas a cada ciclo de combustão.

O balanceamento da potência dos cilindros replica a estratégia do fabricante de equalização da temperatura de escapamento (carga $<75 \%$ ) ou da intensidade de detonação (carga $\geq 75 \%$ ). Ambas são implantadas por meio de controladores do tipo PI (proporcional - integral) atuando sobre a quantidade de combustível individual por cilindro, minimizando a diferença entre sua respectiva temperatura de exaustão, ou intensidade de detonação, em relação à média dos 20 cilindros. A principal diferença, fica, portanto, a cargo da maior sensibilidade dos sensores de pressão à detonação, permitindo um ajuste mais preciso do combustível.

As temperaturas de escapamento são medidas por termopares tipo ' $K$ ' cujos sinais são convertidos no CLP por cartões de aquisição de dados SIEMENS SM331 (com compensação de junta fria por termorresistência PT100) e transmitidas ao LECM a cada segundo através da rede de comunicação CAN CLP. Já a intensidade de detonação é transmitida a partir da SIU a cada ciclo de combustão, conforme detalhado anteriormente.

Além do balanceamento da intensidade de detonação pela distribuição de combustível, o avanço de ignição individual é reduzido instantaneamente quando é observado um ciclo cuja intensidade de detonação ultrapassa os 10 bar, retornando ao avanço nominal gradualmente enquanto novos picos não são observados. Tal função é denominada controle de knock e ajuda a prevenir desligamentos da unidade geradora por detonação, uma vez que o efeito do retardo de ignição é o mais efetivo na prevenção da recorrência da detonação, ao custo de uma combustão defasada e menor eficiência naquele cilindro. A Figura 8 apresenta as malhas de controle dentro da estratégia de controle LECM. 


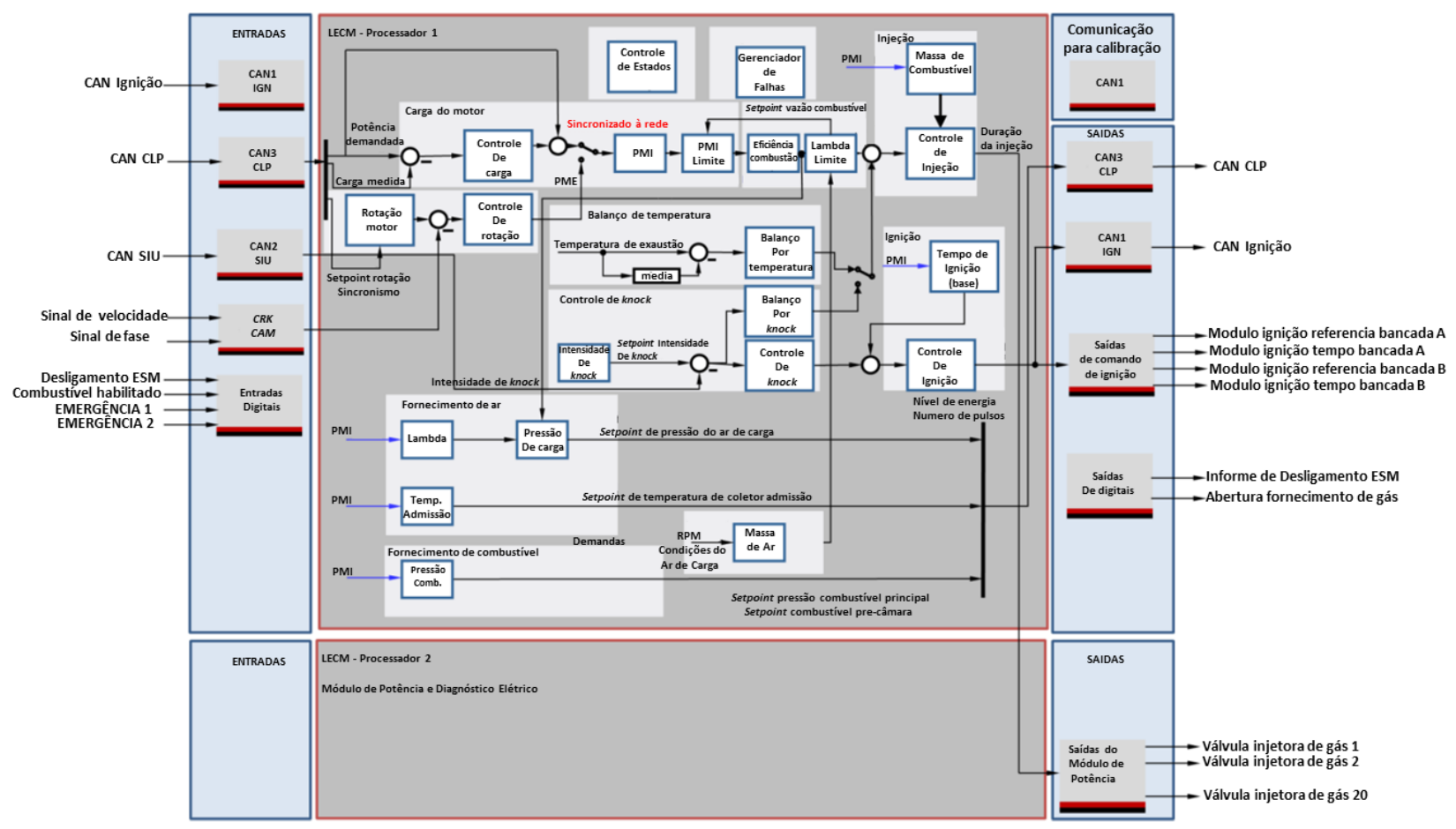

Figura 8. Visão geral da iteração dos sinais de entrada e saídas, e o módulo LECM.

No tocante a detecção de falhas, foram implantadas funções buscando cobrir todas as situações descritas hoje pelo manual do fabricante do motor, reproduzindo ainda a reação correspondente de redução de carga ou desligamento do motor, de modo a assegurar uma operação segura. Dentre estas funções destacam-se:

- Desvio de temperatura do gás de exaustão, das camisas e mancais (CLP)

- Estanqueidade das linhas de gás (CLP)

- Desvio de velocidade do motor (LECM)

- Tempo limite de duração de injeção de gás (LECM)

- Sobrecarga e oscilação de carga (LECM)

- Falha de comunicação (CLP e LECM)

- Falhas relacionadas a pressão no cilindro:

$>$ Sobrepressão (LECM)

$>$ Detonação (LECM)

$>$ Falha de combustão e desativação de um cilindro (LECM)

$>$ Plausibilidade do sensor de pressão (SIU)

\subsection{INTEGRAÇÃO}

Uma vez definidos os requisitos (replicar as funções de controle atual, adicionar medição de pressão no cilindro), os meios físicos (módulo LECM, CLP, e SIUs) e topologia de ligação, é necessário desenvolver as e validar as aplicações de software que recebam informações do ambiente e demandas de operação, convertendo-as em instrução aos diversos atuadores do sistema. Dada a complexidade das iterações entre os diferentes módulos, resposta do motor físico e mesmo a interface com a planta, optou-se por adotar ferramentas amplamente utilizadas na indústria automotiva para validação de software, hardware e sistemas: Model in The Loop (MIL) e Hardware in The Loop (HIL). O novo layout do sistema de controle pode ser visualizado da Figura 9 


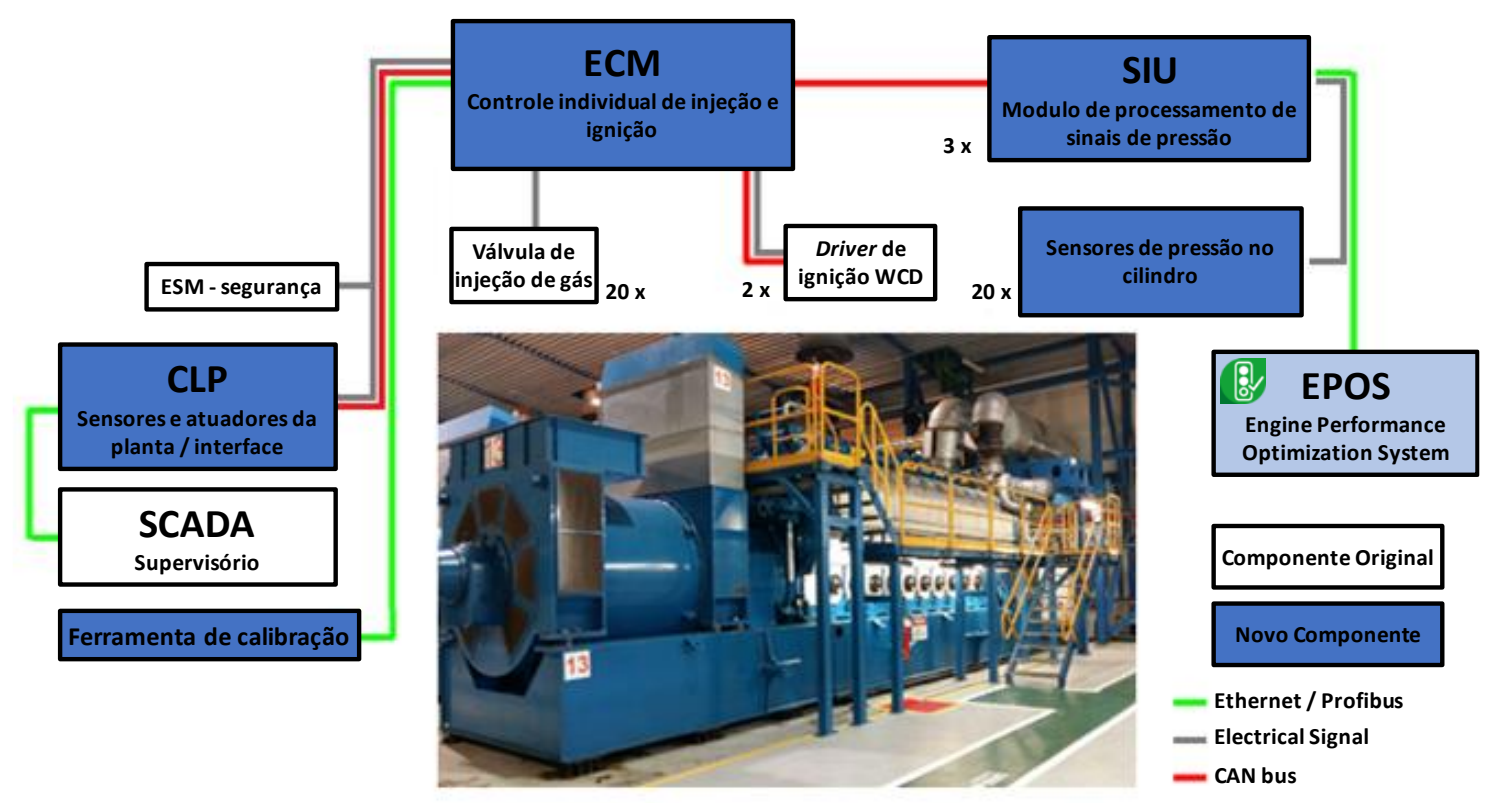

Figura 9. Configuração do novo sistema de controle do motor.

\subsubsection{MODELO UNIDIMENSIONAL DO MOTOR PARA MIL}

Como base a validação das estratégias de controle, um modelo de simulação do motor Wartsila foi desenvolvido considerando os processos que ocorrem em um único cilindro desse motor com auxílio de um programa computacional desenvolvido por um dos autores [15], que considera os processos como admissão da mistura ar-combustível através das válvulas de admissão, troca de calor com as paredes, liberação de calor pela combustão via imposição de uma curva de taxa predefinida e ajustada para as condições de operação, processo de escapamento pelas respectivas válvulas como mostra esquematicamente a Figura 10. A taxa de liberação de calor aplicada como funcões de Vibe foram calculadas a partir das curvas de pressão medidas e de um modelo de duas zonas, com propriedades termodinâmicas variáveis em função das composições e temperaturas dos gases queimandos e não-queimados [15]. Para efeito de cálculo de troca de calor pelas paredes do cabeçote expostas aos gases na câmara de combustão, adotou-se que a área de troca do cabeçote é igual à área da seção transversal do cilindro por se tratar de um cabeçote plano.

Após este modelamento inicial, passou-se ao modelamento do motor completo, considerando os seus 20 cilindros. Para tal etapa, o pacote computacional GT POWER v7.3 foi utilizado, posteriormente tendo sido refinado com uso do pacote AVL BOOST. A partir das curvas de pressão no interior dos 20 cilindros e levantamento das características físicas e geométricas dos componentes como pistões, anéis, bielas e eixo de manivelas, foi possível o desenvolvimento dos modelos de simulação em tempo real que são utilizados para o desenvolvimento de novas estratégias de controle que permitiram uma operação otimizada do motor .Os resultados numéricos do modelo foram validados com medições experimentais das curvas de pressão do cilindro, assim como medições do desempenho do motor, observando-se uma boa aderência entre os valores, como mostram as figuras a seguir. 


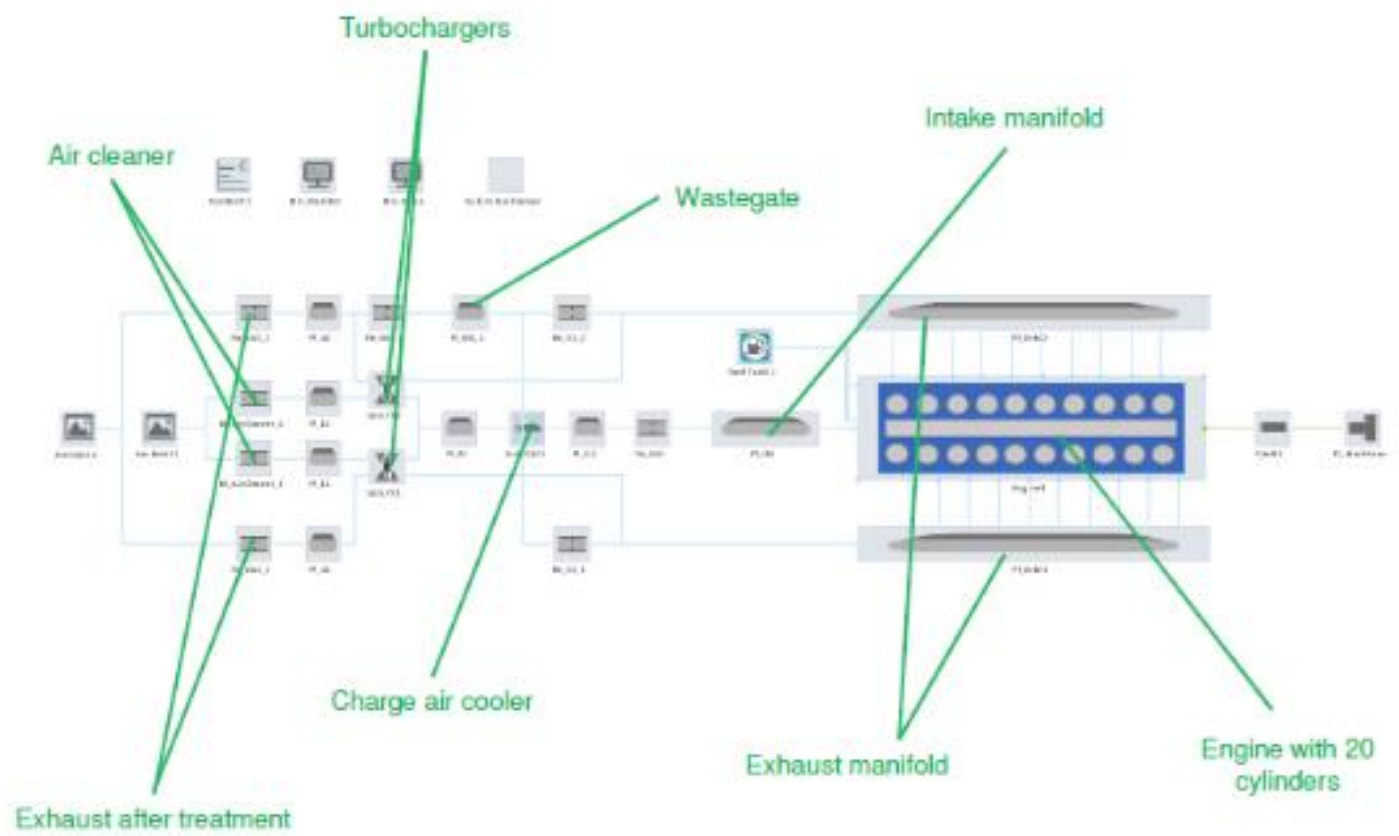

Figura 10. Modelo unidimensional do motor W20V34SG.

A Figura 11 traz as condições que foram simuladas - 4, 8, 12, 16, 18 e 20 bar de pressão média efetiva de eixo (PME) - sempre a $720 \mathrm{rpm}$ de velocidade angular. Também foi calculada a curva de eficiência global do motor, a partir da curva de pressão média efetiva de atrito levantada no motor experimental.

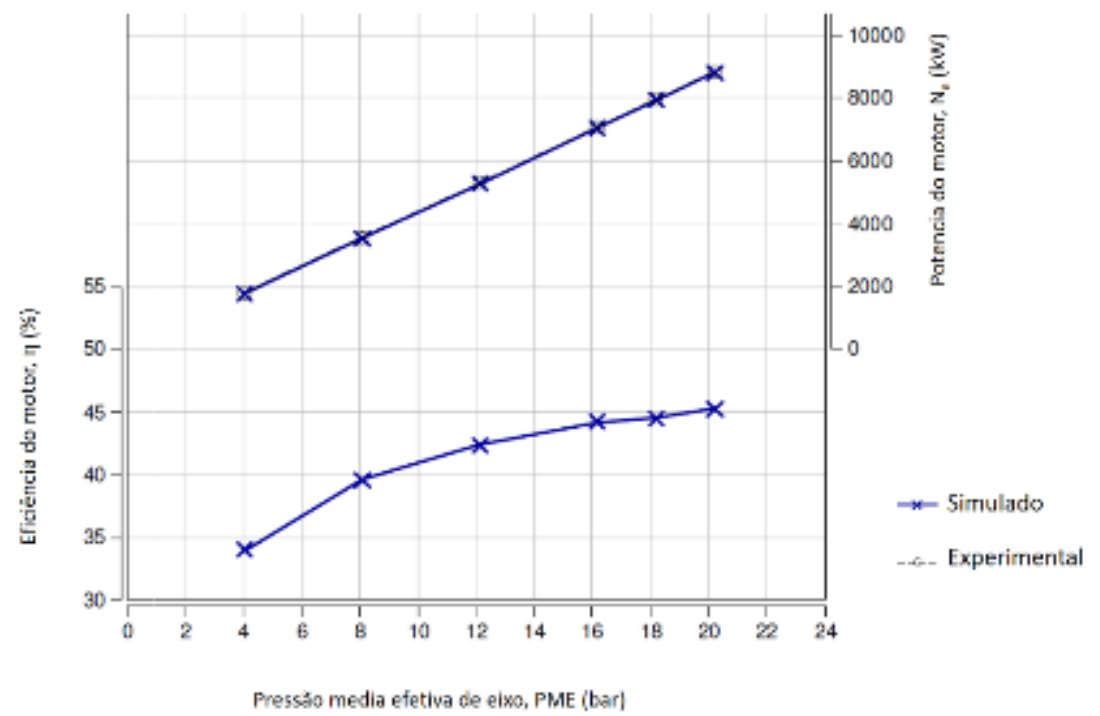

Figura 11. Condições de carga do motor simuladas e medidas.

Como não se conheciam os mapas de desempenho do compressor e da turbina aplicados ao motor Wärtsilä, foram utilizados mapas de componentes similares em dimensões e características, e com pequenos ajustes foi possível atingir aderência entre os resultados de temperaturas e pressões nos coletores de admissão e escapamento do motor, como mostra a Figura 12. A velocidade angular simulada do eixo dos turbo-compressores também teve uma boa aderência aos respectivos valores experimentais. 

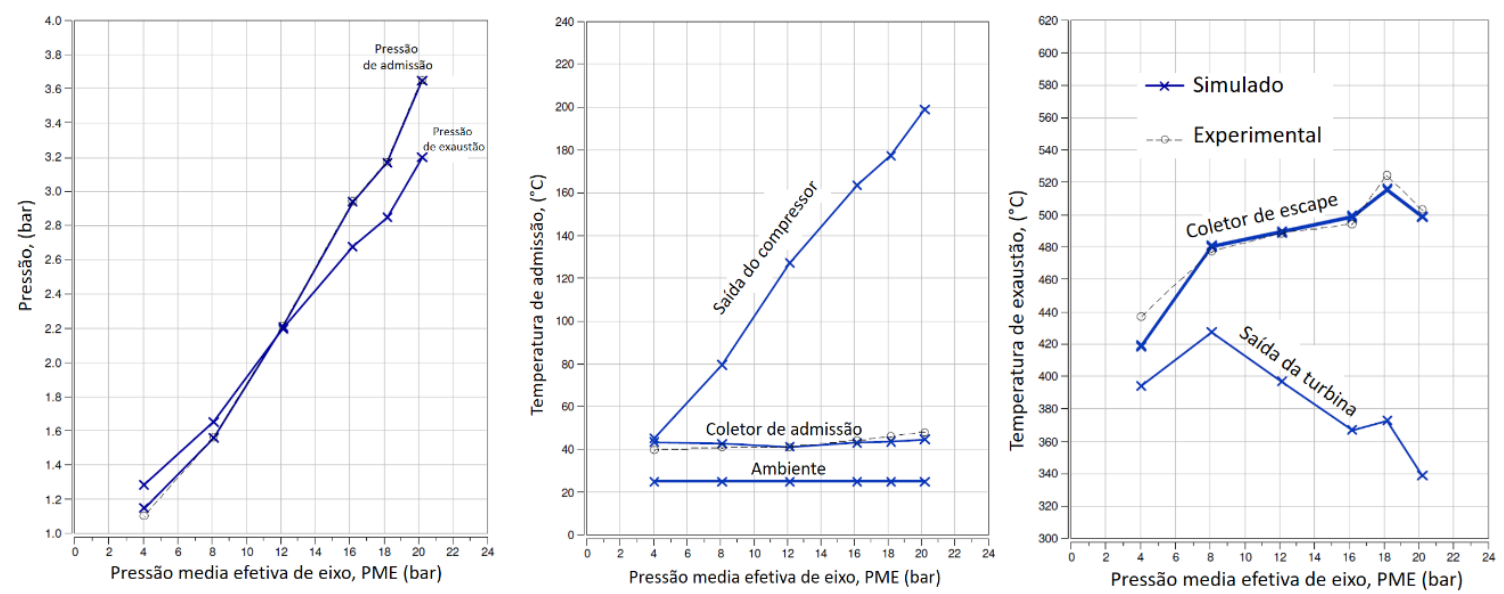

Figura 12. Pressões absolutas (a) e temperaturas de admissão (b) e escapamento (c) em função da Pressão média efetiva de eixo (PME).

O modelo então prevê a pressão máxima de cilindro e a evolução da fração de massa queimada (início da combustão, $50 \%$ e $90 \%$ de fração de massa queimada) como indica a Figura 13. Notase que a partir da pressão média efetiva de eixo de 8 bar as posições angulares onde ocorrem $50 \%$ e $90 \%$ da fração de massa queimada são praticamente constantes, respectivamente iguais a $9^{\circ}$ e $20^{\circ}$ após ponto morto superior de combustão. A Figura 13 mostra ainda o resultado da sobreposição da curva de alta frequência à curva normalmente simulada para efeito de validação da estratégia de detecção de knock pela SIU.

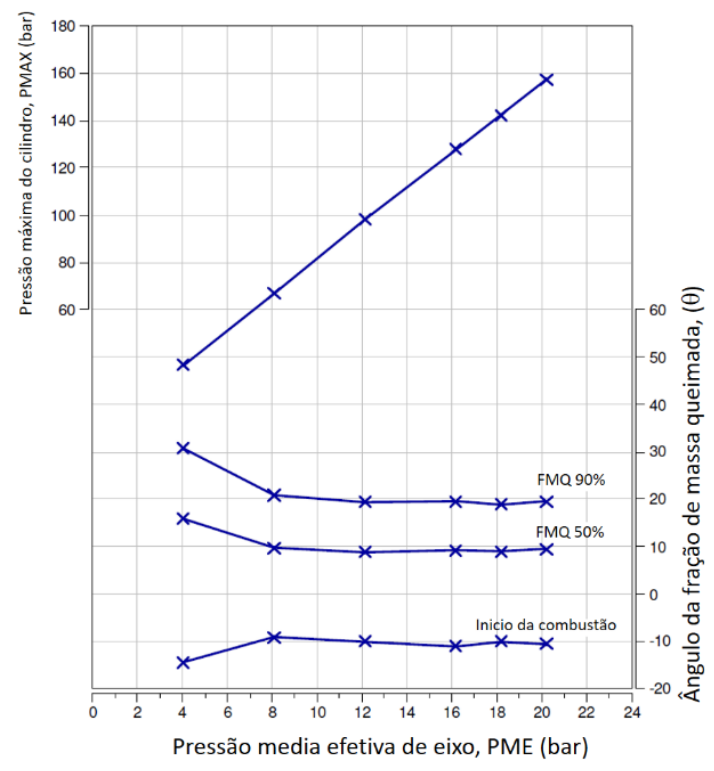

(a)

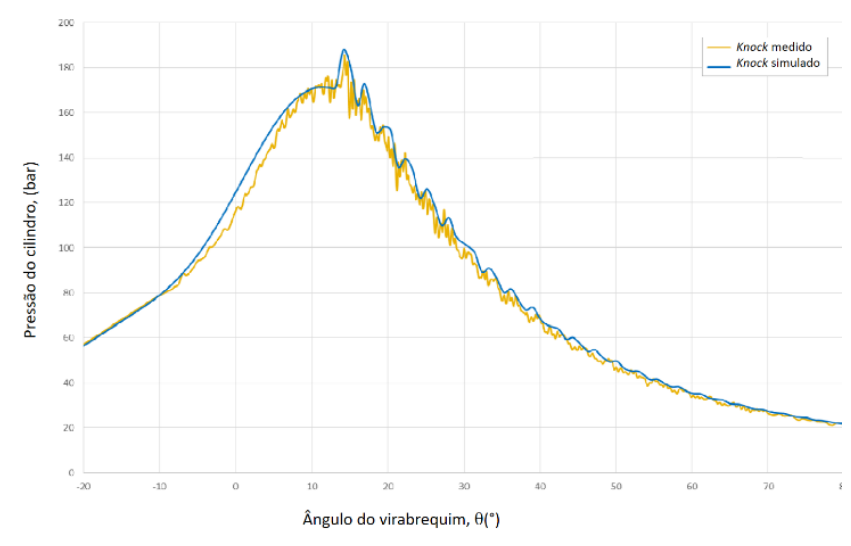

(b)

Figura 13. Evolução da pressão máxima de cilindro e fração de massa queimada em função da PME (a) e comparação da curva de pressão simulada e medida na condição de knock à plena carga (b).

Como a motivação da geração do modelo computacional era possibilitar que estratégias de controle fossem aplicadas a esse modelo a fim de as validar e ajustar constantes e mapas do sistema de controle em bancada, foi necessário adaptar o modelo de simulação a fim de que ele pudesse gerar uma curva de pressão na condição de knock. Uma vez que a modelagem knock envolve cálculos complexos, não seria possível incluir tais rotinas em um modelo que devesse 
rodar em tempo real. Para contornar isso, optou-se por "sobrepor" uma curva de alta frequência sobre a calculada normalmente pelo simulador, de forma que a curva resultante pudesse representar um ciclo real de knock e pudesse sensibilizar adequadamente o canal de entrada da SIU.

O modelo físico-matemático assim gerado reproduz as respostas do motor real e está então apto a servir de "motor virtual" para teste e validação das estratégias de controle-motor.

\subsubsection{VALIDAÇÃO DAS ESTRATÉGIAS DE CONTROLE USANDO MIL/HIL}

O objetivo destas atividades foi avaliar a funcionalidade das estratégias e sua interação com o hardware de controle, identificando potenciais problemas e implementando ações corretivas nos estágios iniciais do desenvolvimento, minimizando riscos de atraso e custos associados.

As estratégias desenvolvidas no software Matlab/Simulink foram inicialmente testadas virtualmente, para verificação do comportamento das funções em relação ao requisito especificado e detecção de possíveis conflitos entre variáveis ou funções que se relacionam. Para isto, a resposta do motor aos estímulos de controle e perturbações ambientais precisam ser simuladas, de modo a se obter um comportamento que represente o sistema real. A este conceito de teste dá-se o nome de Model In the Loop (MIL), bastante utilizado pelos desenvolvedores de software, uma vez que acelera o processo e traz mais confiabilidade nos resultados obtidos. Contudo, a efetividade do processo está relacionada a representatividade do modelo em relação ao comportamento físico da planta e sua capacidade de capturar as principais variáveis que de fato influenciam o problema físico, assim os passos descritos em 2.4.1 foram fundamentais para garantir a confiabilidade dos resultados. O modelo unidimensional do motor foi compilado para o uso no software Matlab/Simulink (formato s-function) através de ferramenta AVL CruiseM.

No próximo passo, as estratégias foram compiladas e os arquivos contendo as instruções para os microprocessadores ( .s37 ) foram gravadas nas memórias dos LECMs, que foram então testadas em bancada, tendo os sinais elétricos de entrada e carga dos atuadores de saída simulados. Trata-se aí do Hardware In the Loop (HIL), onde os componentes físicos - LECM e CLP - tem suas funcionalidades testadas na prática e em tempo real, porém as respostas do motor são simuladas pelo modelo representativo. Com esta abordagem, buscou-se identificar limitações de hardware para execução da estratégia de software, além de iterações inesperadas nos loops de controle executados pelo CLP e LECM.

Findo este processo, a instalação do sistema no primeiro motor pode ser programada, com elevado grau de confiança de que o retorno à operação ocorreria com o mínimo de impacto à geração da usina.

\section{RESULTADOS E DISCUSSÕES}

A unidade geradora 14 (UG14) - cujo motor utiliza o novo sistema de controle integrado ao sistema de diagnóstico e monitoramento - já acumulou mais de 2500 horas de operação em carga plena (status de abril de 2017), e apesar do desafio de substituir o sistema de controle do fabricante e de desenvolver e testar novas estratégias de controle que garantam a segurança da operação, o motor vem apresentando uma média de $96 \%$ de utilização fornecendo $98 \%$ da sua capacidade total de potência elétrica desde o início da implantação do novo sistema. 
Este desempenho é comparável as demais unidades, mesmo operando sob novas estratégias de controle. Como o novo sistema detecta os eventos de knock de uma maneira mais precisa (sensores de pressão no cilindro em vez dos usuais acelerômetros instalados no cabeçote), reduções de carga e desligamentos de segurança (shutdown) devido ao high knock têm sido registrados com maior frequência que os nos motores com o sistema de controle do fabricante. A Figura 14 mostra um dos eventos de desligamento no motor de ensaios devido à baixa qualidade do gás (número de metano abaixo de 70) e os eventos de knock correspondentes, onde o motor é desligado pelo modulo de controle após ter diagnosticado durante 40 ciclos de operação cinco eventos de alto knock (pressão de pico de knock >10bar para mais de $40 \%$ dos ciclos).

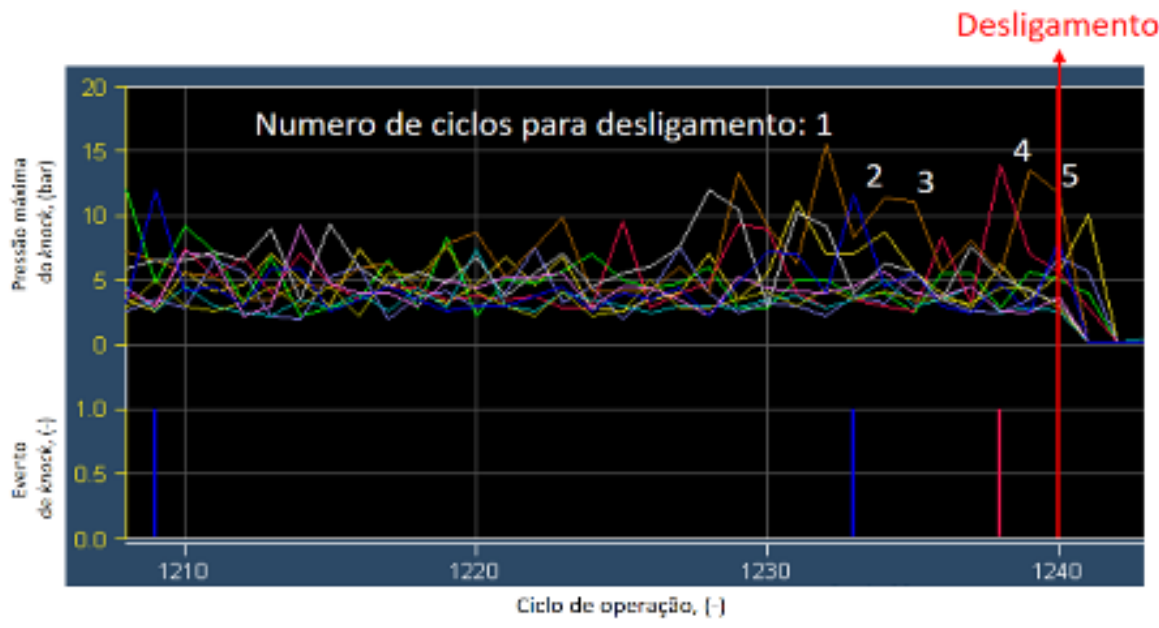

Figura 14. Comportamento de proteção contra high knock do novo sistema de controle.

Em comparação com o sistema de controle do fabricante, a Figura 15 mostra o comportamento da unidade geradora 20, onde são medidos mais de cinco eventos de alto knock em um período de 40 ciclos e o motor continua operando sem nenhum tipo de ação por parte do controlador para garantir a segurança do motor. Isso pode explicar a ocorrência de falhas em componentes como anéis de pistão e anéis de vedação da camisa de motores na planta quando gás de má qualidade é recebido e consumido.

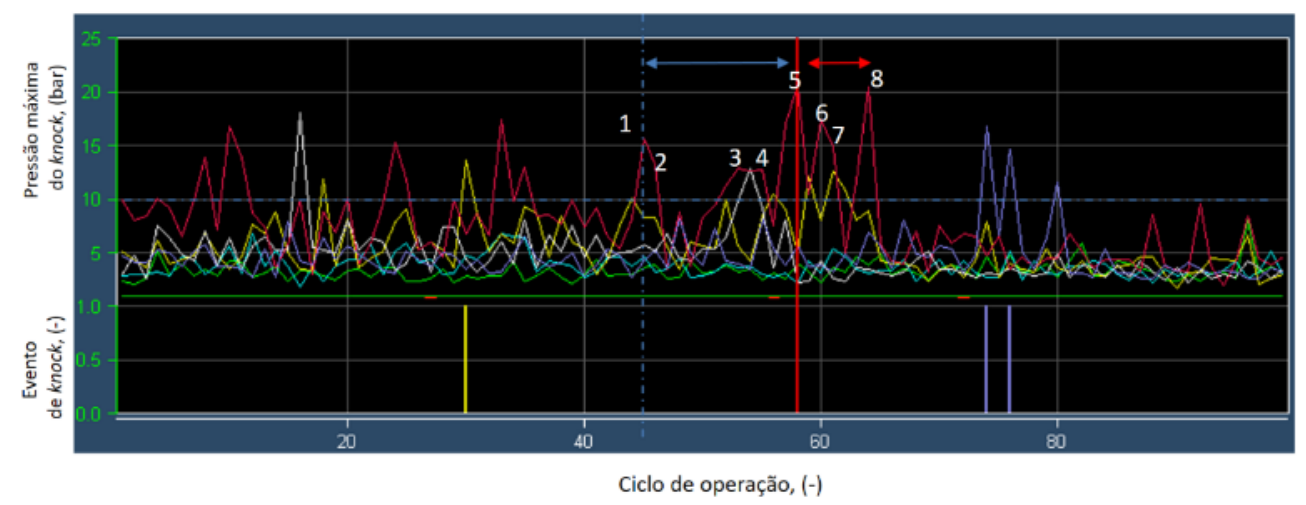

Figura 15. Comportamento da estratégia de controle e proteção contra high knock original do motor.

Um outro ponto notado é que o balanceamento de carga entre os vinte cilindros apresentou melhora significativa quando da utilização do sistema de controle baseado na medição da pressão individual. A Figura 16 evidencia uma menor dispersão da intensidade de knock entre os cilindros da UG14 para diferentes condições de qualidade do gás em comparação com outras 
unidades geradoras sob as mesmas condições. Já Figura 17 indica uma menor dispersão entre as pressões máximas observadas nos cilindros quando comparado a um motor com sistema de controle original, nas mesmas condições operacionais.

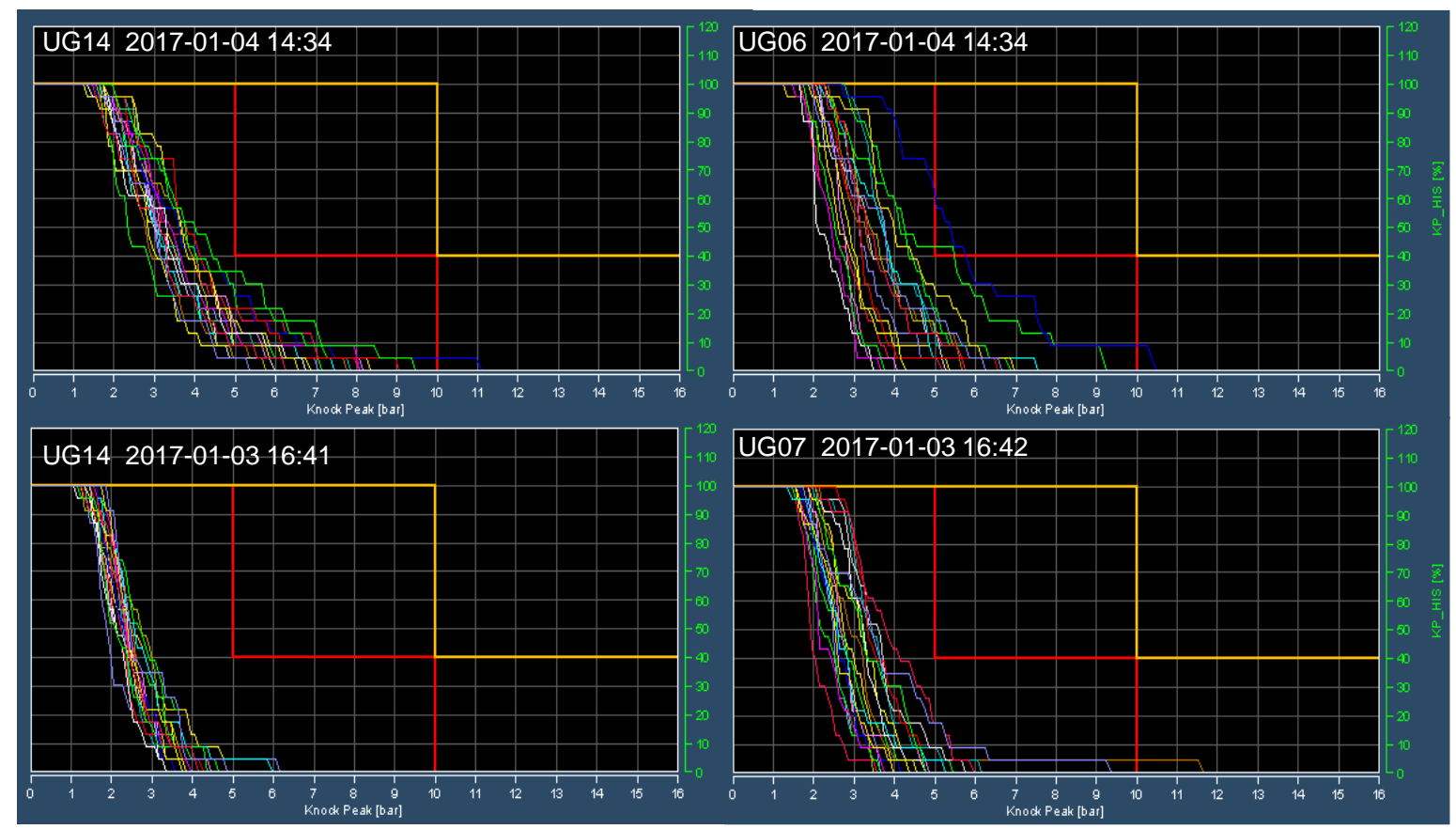

Figura 16. Comparação entre margem de knock por histograma de intensidade de detonação para diferentes dias e qualidades de gás (UG14, novo sistema de controle, UG06 e UG07 sistema original).
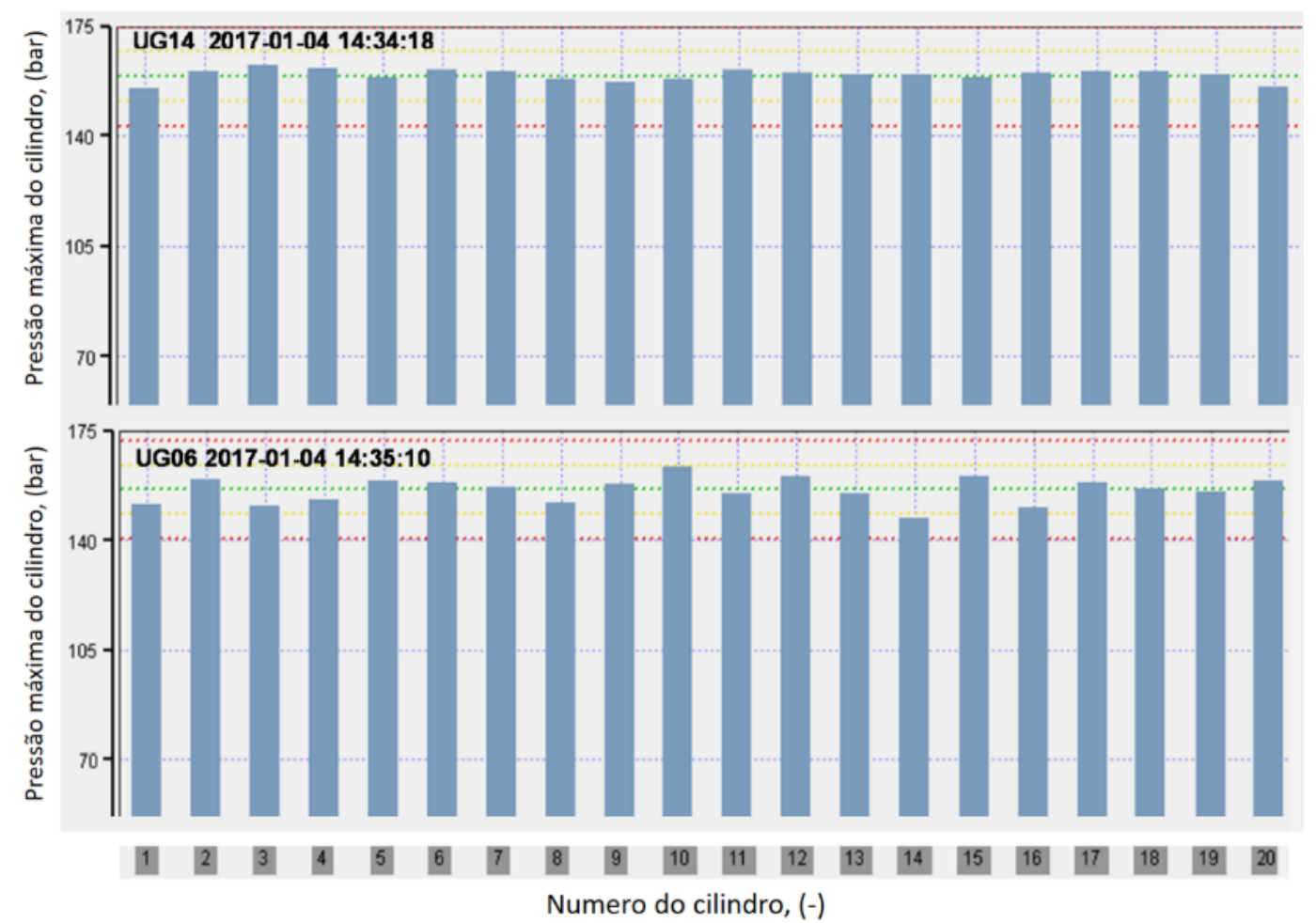

Figura 17. Comparação entre balanceamento das pressões máximas dos vinte cilindros (UG14, novo sistema de controle, UG06 sistema original). 
Além dos resultados relacionados ao sistema de controle, o sistema de monitoramento e diagnóstico tem detectado vários problemas que foram preditos e solucionados antes que ocasionassem falhas catastróficas no motor reduzindo ainda o tempo de indisponibilidade forçada de máquinas, que poderiam impactar negativamente na operação e resultados econômicos da usina. No último ano mais de 130 intervenções foram registradas nas 24 unidades geradoras - por orientação do sistema de diagnóstico - sendo destas apenas 2 intervenções de ajuste de válvulas executadas na UG 14 nos últimos 3 meses. Seria precipitado concluir que este é um resultado direto das novas estratégias de controle, porém é certamente um excelente indicativo da eficácia da integração dos sistemas e dos benefícios que este trará.

\section{CONCLUSÃO}

Foi criado e implantado em ambiente industrial um conceito de integração de um sistema de monitoramento e diagnóstico inteligente a um sistema de controle aberto para modificações nas suas estratégias, operando em malha fechada. Esse sistema integrado permite aos operadores de motores de combustão interna alternativos que utilizam gás natural como combustível uma otimização do desempenho para as condições operacionais da usina, considerando não só os sinais da pressão dos cilindros, mais também a condição atual do motor e seus componentes. Esse sistema pode ser utilizado não só no segmento de geração de energia elétrica, mas também em sistemas de propulsão marítima, sejam eles baseados em motores ciclo Otto ou Diesel.

A instalação e a integração completa de um sistema de monitoramento e diagnóstico com um novo sistema de controle aberto e integrado ao supervisório da usina foram concretizadas em uma das unidades geradoras da UTE LORM, onde o motor tem demonstrado uma operação confiável e estável desde novembro de 2016 (desde 2014 com monitoramento e diagnóstico). Continuando com o processo de desenvolvimento, o motor está sendo monitorado permanentemente e ajustes nas estratégias de controle estão sendo executadas para otimizar a operação do motor para uma condição de maior eficiência. Assim estão sendo instalados medidores de vazão de combustível individuais que permitam uma medição dos ganhos potenciais na eficiência e consumo de combustível do motor, bem como a inclusão da composição do gás combustível como variável de controle na previsão da potência disponível. Considerando-se que o Brasil possui um parque termelétrico significativo de usinas baseadas em motores de combustão, esse sistema de monitoramento poderia ser facilmente aplicável às demais plantas, sobretudo em um momento em que a permanência destas instalações ao final dos contratos de fornecimento atualmente em vigência pode depender da sua conversão para uso de gás natural, onde a eficiência no desempenho será imprescindível para assegurar a sustentabilidade econômica das empresas.

\section{AGRADECIMENTOS}

Este projeto está sendo desenvolvido no âmbito do Programa de Pesquisa e Desenvolvimento Tecnológico do Setor de Energia Elétrica regulado pela ANEEL, com o título Desenvolvimento de técnicas, algoritmos de diagnóstico preventivo de problemas, otimização da eficiência energética da combustão e balanceamento da potência de cilindros de motores estacionários a gás natural, código PD-6932-0115-2014, cadastrado em 12/2014, sendo executado pela empresa CAAR Pesquisa e Engenharia e suportado financeiramente pela empresa Linhares Geração S.A. Os autores agradecem à Linhares Geração S.A. pelo apoio e incentivo à pesquisa que vem buscando aumento de eficiência e redução dos custos operacionais de sua planta. A 
cessão das instalações, do motor de ensaio, participação de colaboradores especialistas e pesquisadores da LGSA foram imprescindíveis para execução desse trabalho.

\section{REFERÊNCIAS}

[1] WIBBERLEY, Peter; CLARK, Christopher. An Investigation of Cylinder Pressure as Feedback for Control of Internal Combustion Engines. SAE Technical Paper 890396, 1989.

[2] PESTANA, Greg. Engine control methods using combustion pressure feedback. SAE Technical Paper 890758, 1989.

[3] POWELL, David J. Engine control using cylinder pressure: past, present, and future. ASME - Journal of Dynamic Systems, Measurement, and Control, vol. 115, n. 2B, pp. 343-350, 1993.

[4] SELLNAU, Mark C.; MATEKUNAS, Frederic A.; BATTISTON, Paul A.; CHANG, Chen-Fang; LANCASTER, David R. "Cylinder-pressure-based engine control using pressureratio-management and low-cost non-intrusive cylinder pressure sensors," SAE Technical Paper 2000-01-0932, 2000.

[5] AMIRANTE, Ricardo; CASAVOLA, Caterina; DISTASO, Elia; TAMBURRANO, Paolo. Towards the development of the in-cylinder pressure measurement based on the strain gauge technique for internal combustion engines. SAE Technical Paper 2015-24-2419, 2015.

[6] WIDESKOG, Mikael. Introducing the world's largest gas engine. Wärtsilä technical journal in detail, Helsinki, 01/2011. Disponível em: http://twentyfour7.studio.crasman.fi/pub/web/pdf/magazine+pdfs/ID0111-WWW-HQ.pdf. Acesso em 19/05/2017.

[7] WIDESKOG, Mikael; ÅSTRAND, Ulf. The Wärtsilä 34SG gas engine's output increased to $10 \mathrm{MW}$," Wärtsilä technical journal in detail, Helsinki, 01/2010. Disponível em: http://twentyfour7.studio.crasman.fi/pub/web/pdf/magazine+pdfs/ID0110-WWW-HQ.pdf. Acesso em 19/05/2017.

[8] PORTIN, Kaj; HELLÉN, Jenny. Gas engine control based on integrated cylinder pressure measurement. 6th Dessau Gas Engine Conference, Dessau, 2009, pp. 208-219.

[9] EGGERS, Joachim; GREVE, Martin; BIRNER, Matthias. Cylinder pressure based combustion control. 6th Dessau Gas Engine Conference, Dessau, 2009, p. 164-185.

[10] TRAPP, Christian; BÖWING, Robert; BIRGEL, Andreas; MADL, Wolfgang; FAHRINGER, Albert; NOTA, Fabrizio. GE's J920 gas engine - 10.3 MW power at up to 50\% electrical efficiency. 10th Dessau Gas Engine Conference, Dessau, 2017, p. 67-82.

[11] WÄRTSILÄ. Wärtsila 34SG Power Plant Product Guide. 2008.

[12] HEYWOOD, John B. Internal Combustion Engine Fundamentals. 1a ed., McGraw-Hill, 1988, p. 930.

[13] AVL. AVL EPOS ${ }^{\mathrm{TM}}$ Gas. Product Sheet EPOS Gas. Disponível em https://www.avl.com/documents/10138/1246816/Product+Sheet+EPOSGas.pdf. Acesso em $17 / 05 / 2015$.

[14] MOHR, Hinrich; HUELSER, Holger; KORSUNSKY, Evgeny.; MAYRHOFER, Norbert.; TEICHMANN, Ruediger. Approach for condition monitoring as integral part of engine and auxiliary systems," CIMAC - Conseil International des Machines a Combustion, pp. 1-9, 2007.

[15] ZABEU, Clayton B.; Nigro, Francisco E. B. Análise da combustão em motores baseada na medição de pressão, 1999. 